\title{
Experimental Study for Enhancement the Cooling System and Exhaust Gasses for Gasoline Automotive Engine Using Nano-Fluid.
}

\author{
M. Nagib ${ }^{\text {a; }}$ S.M. Elshamy ${ }^{\text {b }}$; H. Zafan ${ }^{\text {c }}$ H.H. Dadoura ${ }^{\text {c }}$ \\ ${ }^{a}$ Research student in High technological institute. \\ ${ }^{\mathrm{b}}$ Ass. Prof. in High Institute of Engineering, $6{ }^{\text {th }}$ October, Egypt. \\ ${ }^{c}$ Prof. Dr. in Automotive Engineering Department, Helwan University, Egypt.
}

Corresponding author, E-mail address: smelshamy@csi.edu.eg

\begin{abstract}
Adding of nanomaterial to car radiator fluid for 4-stroke gasoline engine was investigated experimentally at different Nanofluid concentrations with different flow rates for variable car speeds and number of passengers. The fluid temperature and exhaust gases emissions have been carried out. Results demonstrate that the increasing of Nanofluid concentration and high fluid circulation rates can improve the heat transfer of the engine radiator response; also using Nanofluids reduces the $\mathrm{CO}$ and $\mathrm{NO}_{\mathrm{x}}$ emissions of the engine exhaust gasses, while the $\mathrm{CO}_{2}$ ratio has been increased.
\end{abstract}

Keywords: Nanofluid; Car Radiator; Emissions; Nusselt Number

\section{Introduction}

Continues technology development in automotive manufacture has been increased dramatically the demand for high efficiency of engines. The high efficiency of engine is not only based on its performance but also for less fuel consumption and low rate emission. As result reducing a vehicle volume by optimizing design and size of a radiator is a necessity for making the world green. So far, few studies are reported for nanofluids heat transfer enhancement for Car Radiator (CR) with real load applications, car on a road and link this performance with engine emission levels. 
The fluids used for transferring heat such as water and ethylene glycol exhibit very law thermal conductivity. So, there is a need for new and innovative heat transfer fluids for enhancement the process of heat transfer rate in CR. Nanofluids seem to be potential replacement of conventional coolants in automotive engine cooling systems. Recently there have been considerable experiments highlighting the effect of Nanofluids in enhancement the heat transfer rate. Ali et al. [1] have experimentally investigated the performance of an aluminum CR using water based Zinc Oxide $\mathrm{ZnO}$ Nanofluids. They studied its heat transfer performance. It ensured that heat transfer enhancement compared to pure water at the best concentration of $0.2 \%$ vol., which enhance the heat transfer up to $46 \%$ compared to the base fluid. Ebrahimi et al. [2] have experimental studied Silicon Oxide $\mathrm{SiO}_{2}$ Nanofluids flowing in $\mathrm{CR}$ for different working conditions. Increase of liquid inlet temperature, nanoparticle volume fraction, and its Reynolds number they observed that Nusselt number increased. Sandhya et al. [3] reported heat transfer enhancement utilizing ethylene glycol and water based Titanium Oxide $\mathrm{TiO}_{2}$ Nanofluids as an automobile radiator coolant for range of $\mathrm{Re}=4000-15000$. Increasing in the fluid circulation rate improves the heat transfer response. Sany et al. [4] have investigated the performance of compact heat exchanger (CR) experimentally. $E$-NTU method was used to perform the values of Nusselt number and heat transfer coefficient in a wide range of operation conditions. The heat transfer coefficient and Nusselt number improved by $50 \%$ due to better air distribution in radiator compared with actual conditions in an automobile. Tomar and Tripathi [5] carried out an experimental study using mixture of ethylene glycol + water $(50+50)$ combination with Aluminum Oxide $\mathrm{AL}_{2} \mathrm{O}_{3}$ Nanoparticles in a CR. $\mathrm{AL}_{2} \mathrm{O}_{3}$ Nanoparticles size $40 \mathrm{~nm}$ were used with volume concentration of $(0.1 \%, 0.5 \%, 1.0 \%)$ and flow rate range 2$5 \mathrm{l} / \mathrm{min}$. They found that the thermal conductivity of the fluid increased almost linearly with temperature. Heat transfer rate was increased with increasing volume concentration of Nanoparticle. Leong et al. [6] investigated the effect of ethylene glycol-based copper Nanofluids in an automotive cooling system with volume concentration $0.2 \%-2.0 \%$. They found that heat transfer rate increased with increasing in volume concentration of nanoparticles where $3.8 \%$ heat transfer enhancement achieved with addition of $2 \%$ copper Nanoparticles. The thermal performance of radiator is enhanced about $42.7 \%$ and $45.2 \%$ for pure ethylene glycol and ethylene glycol with $2 \%$ of copper Nanoparticles respectively. By adding $2 \%$ copper Nanoparticles reduction by $18.7 \%$ of air frontal area is achieved. Raja et al. [7] studied the effect of heat transfer enhancement and $\mathrm{NO}_{\mathrm{x}}$ emission in single cylinder Diesel engine using $\mathrm{AL}_{2} \mathrm{O}_{3}$ Nanofluid as coolant under laminar flow conditions and Nanofluid volume concentrations $0.5 \%, 1.0 \%, 1.5 \%$ and $2.0 \%$. Overall heat transfer coefficient at that Nanofluid concentration was enhanced by $11 \%, 18 \%, 23 \%$ and $25 \%$ respectively under no load conditions. Also, the utilization of nanofluids resulted in $12.5 \%$ reduction of $\mathrm{NO}_{\mathrm{x}}$ emissions at full load and about 3-5\% at no load and part load. Hussein et al. [8] investigated the enhancement of heat transfer using Nano-powders of $\mathrm{TiO}_{2}$ and $\mathrm{SiO}_{2}$, the test was on $\mathrm{CR}$ under certain conditions. Their results showed that with increasing volume flow 
rate Nusselt number increased. Senthilraja et al. [9] performed an experimental work to study the exhaust emissions of NOx, exhaust gas temperature and specific fuel consumption under different load conditions utilizing Cupper Oxide $\mathrm{CuO} /$ water Nano-fluid for three different volume concentrations of $0.05,0.1$, and $0.2 \% \mathrm{vol}$. They illustrated that even at low volume concentrations, have a significant influence on exhaust emissions. The specific fuel consumption reduced by $8.6 \%, 15.1 \%$ and $21.1 \%$ with specific Nanofluid volume concentrations. NOx emissions were found that it decreased by all volume concentrations of $\mathrm{CuO} /$ water Nanofluids respectively. Ahmed M. [10] replaced the conventional cooling system by electronically controlled components, electrical variable speed pump and variable speed fan. A PID controller and linear quadratic regulator are proposed to design an engine cooling system operation with different concentrations of $\mathrm{AL}_{2} \mathrm{O}_{3}$ Nano-Fluid in an automobile radiator. Naraki et al. [11] searched laminar flow regime $(100 \leq$ $\mathrm{Re} \leq 1000$ ) in a car radiator. The overall heat transfer coefficient of $\mathrm{CuO} / \mathrm{water}$ Nanofluids was detected, where the overall heat transfer coefficient increases. Each of Nanofluid volumetric flow rate, inlet temperature and concentration has $23 \%$, $22 \%$ and $13 \%$ contribution in the overall heat transfer coefficient, respectively.

The above literature review showed that most previous work related to utilize Nanofluid inside a CR without incorporation with car load and /or real complete car engine just a CR inside wind tunnel attached with source of heating. Consequently, the novelty of the present work depends on these two main concepts: first, carryout the performance of real car engine with various loads on the road to find out the heat transfer rate and engine exhaust emission for different Nanofluid concentrations

In this study, Aluminum Oxide $\mathrm{AL}_{2} \mathrm{O}_{3}$ / water Nanofluid are prepared for different concentrations of $0.2 \%, 0.6 \%$ and $1.0 \%$ vol. also, for different car speeds 30,60 and $90 \mathrm{~km} / \mathrm{h}$. with 2 and 4 passengers to study the heat transfer enhancement and engine emission variations.

\section{Nanofluid Preparation}

Assuming that the Nano-powder is fully dispersed within the base fluid, i.e. the particles distribution can be considered homogeneous throughout the system. Preparation of stable Nano-fluids is of great significance in heat transfer applications of nanofluids. Un-well prepares Nanofluid will render two phase heat transfer (i.e. sold-liquid). Also, there is another problem which is aggregation of nanoparticles so it creates large particles (in micrometer), thus terminate the Nano related discussions. Aluminum Oxide $\left(\mathrm{AL}_{2} \mathrm{O}_{3}\right)$ nanoparticles used in this study are approximately spherical with diameter of about $50 \mathrm{~nm}$. The amount of Nanopowder required for a certain percentage of volumetric concentration $\varphi$ is estimated from equation (1) as a function of the volume of the Nano particles Volume $_{p}$;

$$
\text { volume concentration }, \varphi(\%)=\frac{\text { Volume }_{p}}{\text { Volume }_{\text {Total }}}
$$




$$
\text { volume concentration , } \varphi(\%)=\left[\frac{\frac{m_{p}}{\rho_{p}}}{\frac{m_{p}}{\rho_{p}}+\frac{m_{f}}{\rho_{f}}}\right] \times 100
$$

The Nanofluid solution as function of the particles and fluid masses $m_{p}, m_{f}$ and their densities $\rho_{p}$, and $\rho_{f}$ was kept in a sonication continuously for about 8 hours to achieve uniform dispersion. The effective physical properties of the studied mixtures can be evaluated using some classical formulas as usually used for two phase fluids. These relations have been used to predict Nanofluid physical properties like density, viscosity, thermal conductivity and specific heat at different concentrations [10]. In this paper, the following correlations were used to calculate these physical properties of Nanofluid:

$$
\begin{aligned}
\rho_{n f} & =(1-\varphi) \rho_{f}+\varphi \rho_{p} \\
C_{p_{n f}} & =\frac{\varphi\left(\rho C_{p}\right)_{p}+(1-\varphi)\left(\rho C_{p}\right)_{f}}{\rho_{n f}} \\
\mu_{n f} & =\mu_{f}(1+2.5 \varphi) \\
\frac{K_{n f}}{K_{f}} & =\frac{k_{p}+2 k_{f}+2\left(k_{p}-k_{f}\right) \varphi_{e f f}}{k_{p}+2 k_{f}-2\left(k_{p}-k_{f}\right) \varphi_{e f f}}
\end{aligned}
$$

In the above equations, the subscripts " $p$ ", "f" and "nf" refer to the particles, water, and Nanofluid respectively.

\section{Experimental Setup}

BYD Automobile, 4-stroke and 4-cylinder Spark ignition engine is used to investigate the heat performance and exhaust gases emission. A complete cooling system for automobile engine is illustrated in Figure 1.

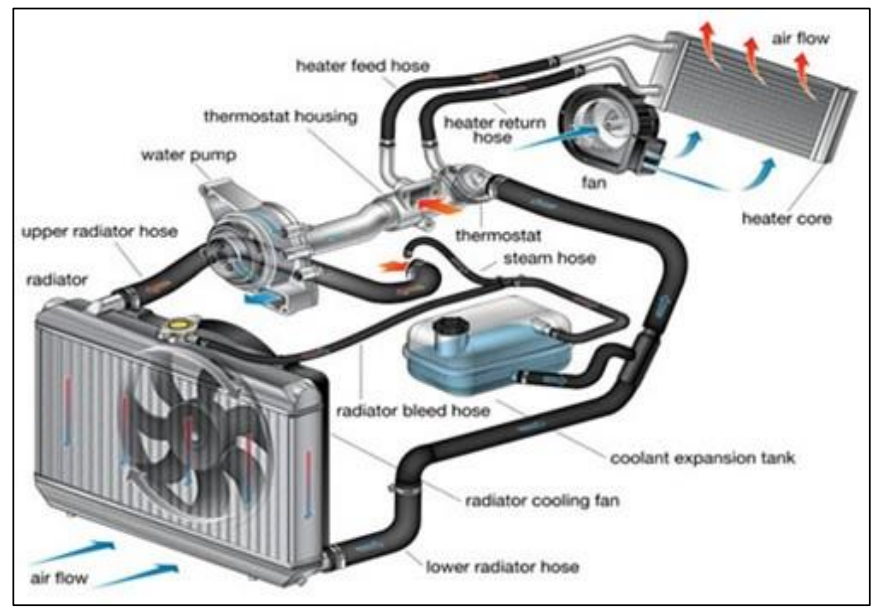

Fig.1: Schematic diagram of automobile cooling system

The main components of cooling system consist of CR, fan, water pump and flow pipes to connect inlet and outlet of CR to engine body where cooling liquid extract 
heat from engine. Flow meter is attached to flow line to measure flow rate of cooling liquid where pump gives a certain flow rate at a certain engine speed. 4 Thermocouples were used; 2 of them installed to the radiator inlet and outlet flow pipes as shown in Figure 2 to detect radiator inlet and outlet coolant temperatures. The other 2 thermocouples are installed at the center of the radiator surfaces (both sides). The temperatures are measured by 4 digital multimeters AUTONICS Temperature Controller TC4M-14R. After installation of all thermocouples the CR was placed again.

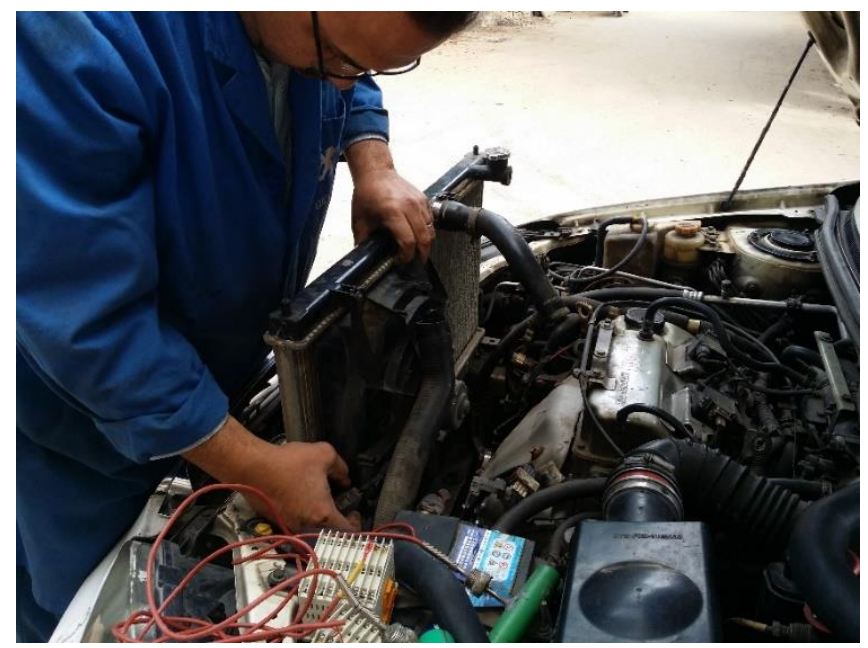

Fig.2: Fixing $\mathrm{CR}$ in its original place after mounting thermocouple sensor

The CR is charged with specific amount of Nanofluid with certain value concentration from 0.0 to $1.0 \%$ vol. The vehicle start motion on a level road with certain occupants of 2 or 4 at travel speeds 30,60, and $90 \mathrm{~km} / \mathrm{h}$. At high steady temperature, all radiator thermocouples readings and ratios of engine exhaust gas emission were carried out from. The experiments have been performed for different recharging of the $\mathrm{CR}$ with anther Nanofluid concentration.

\section{Uncertainty Analysis}

Experimental uncertainties are calculated utilizing the method developed by Kline and McClintock [12]. The uncertainty range of Reynolds number comes from the errors in the measurement of volumetric flow rate hydraulic diameter of tubes. Also, the uncertainty of Nusselt number refers to the errors in the measurements of volume flow rate, and all detected temperatures. The maximum calculated uncertainties in Reynolds no. and Nusselt no. were found to be $\pm 3.1 \%$ and $10.2 \%$ respectively. The accuracies of various measuring devices are shown in Table1.

Table 1: Accuracies of the detection devices

\begin{tabular}{|l|l|l|l|}
\hline Sensor / type & Reference & Description & Accuracy \\
\hline Water flow meter (F-44750L-12) & Blue-White & Flow rate & $\pm 4 \%$ \\
\hline Digital thermometer (TC4M-14R) & AUTONICS & Temperature & $\pm 0.1^{\circ} \mathrm{C}$ \\
\hline Digital air flow meter (DVM+) & Supco & Air speed & $\pm 3 \%$ \\
\hline
\end{tabular}




\begin{tabular}{|l|l|l|l|}
\hline Calibrated Ruler & Local & Tube length & $\pm 0.88 \%$ \\
\hline Exhaust Gas Analyzer (AGS200) & Brain Bee & Exhaust gases & $\mathrm{CO} \pm 0.01 \%$ \\
& & & $\mathrm{CO}_{2} \pm 0.1 \%$ \\
& & & $\mathrm{NOx} \pm 0.1 \%$ \\
\hline
\end{tabular}

\section{Mathematical Modeling}

The heat transfer coefficient in the radiator is estimated for the Nanofluid coolant as well as the air flowing over the fins of the radiator. To get heat transfer coefficient and congruent Nusselt number, the following steps has been performed.

$$
\begin{aligned}
& Q=h A\left(T_{b}-T_{w}\right) \\
& \text { peripheral area, } A=2[(L \times H)+(L \times W)]
\end{aligned}
$$

Where

$\boldsymbol{L}$ is the length, $\boldsymbol{W}$ is the width and $\boldsymbol{H}$ is height of flattened tube of CR.

$$
Q=m C_{P} \Delta T=m C_{P}\left(T_{\text {in }}-T_{\text {out }}\right)
$$

Regarding the equality of heat in above equations

$$
\begin{aligned}
N u & =\frac{h_{\text {exp }} \cdot d_{h y}}{k}=\frac{m C_{p}\left(T_{\text {in }}-T_{\text {out }}\right) D_{h y}}{A\left(T_{b}-T_{w}\right) k} \\
D_{h y} & =\frac{4 \times \text { Tube surface area }}{\text { Perimeter of the tubes }} \\
R e & =\frac{\rho u D_{h y}}{\mu}=\frac{4 m}{\pi D_{h y} \mu}
\end{aligned}
$$

In Equation (10), $\mathrm{Nu}$ is average Nusselt number for the whole radiator,

\section{Result Presentation and Discussion}

The results were divided into two categories where the first deal with heat transfer and the second one deal with emissions of gases. Before conducting systematic experiments on the application of Nanofluids in the radiator, some experimental runs with pure water were carried out in order to check the reliability and accuracy of the experimental setup. Comparison was made between the experimental data and three well-known empirical correlations: one of them suggested by Gnielinsky [13] and the other developed by Petukhov et al. [14] and Dittus-Boelter [15] as shown in Figure 3. These three relations are shown in Equations (13, 15 and 17) respectively.

$$
N u=\frac{\left(\frac{f o}{8}\right) \operatorname{Re} \cdot \operatorname{Pr}}{1.07+12.7\left(\frac{f}{8}\right)^{0.5}\left(\operatorname{Pr}^{\frac{2}{3}}-1\right)} \quad \text { Gnielinsky eq. }
$$

Where $3 \times 10^{3}<\operatorname{Re}<5 \times 10^{6}$, and $0.5<\operatorname{Pr}<2000$ 


$$
\begin{aligned}
& f=(1.82 \log (R e)-1.64)^{-2} \\
& \overline{N u}=\frac{\left(\frac{f}{2}\right)(R e-1000) P r}{1+12.7\left(\frac{f}{2}\right)^{0.5}\left(\operatorname{Pr}^{\frac{2}{3}}-1\right)} \quad \text { Petukhov et al. eq. }
\end{aligned}
$$

For $2300<\operatorname{Re}<5 \times 10^{6}$, and $0.5<\operatorname{Pr}<2000$

$$
\begin{aligned}
& f=(1.58 \operatorname{Ln}(R e)-3.82)^{-2} \\
& \overline{N u}=0.0236 \operatorname{Re}^{0.8} \operatorname{Pr}^{0.3} \quad \text { Dittus-Boelter eq. }
\end{aligned}
$$

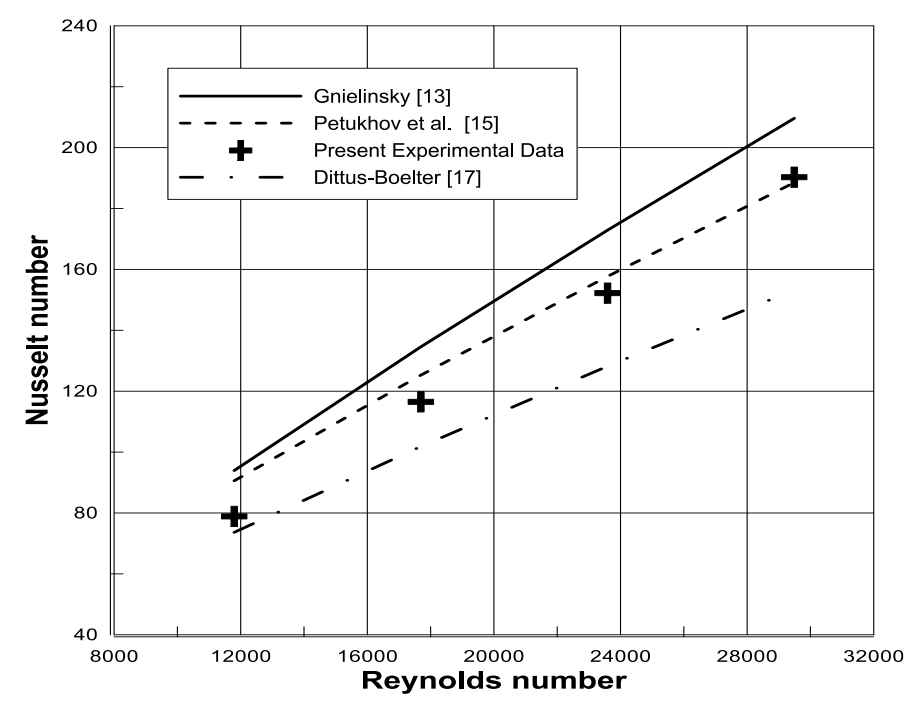

Fig.3: Experimental results of pure water in comparison with the existing correlations.

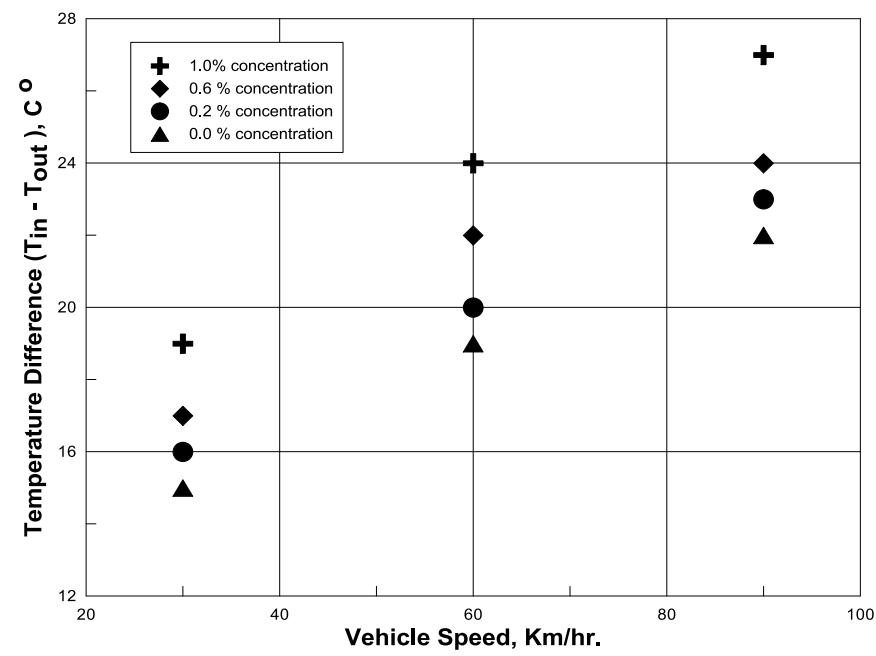

Fig.4: Variation of temperature difference with vehicle speed with different Nanofluid concentrations with 2 passengers 
Figure 4 shows the temperature difference between inlet and outlet of radiators as a function of vehicle speed for pure water and three different Nanofluid concentrations. It shows that the temperature difference increase it means more heat dissipated from car radiator at certain vehicle speed (same water flow rate) .one can clearly observe at the same vehicle speed temperature difference increase with augmentation of Nanoparticle volume concentration.

Variation of $\mathrm{Nu}$ number with Reynolds number for both 2 and 4 passengers at variable Nanofluid concentrations is shown in Figures (5, and 6). Both illustrate that with increasing Reynolds number Nusselt number increase and also increase with increasing Nanofluid concentration.

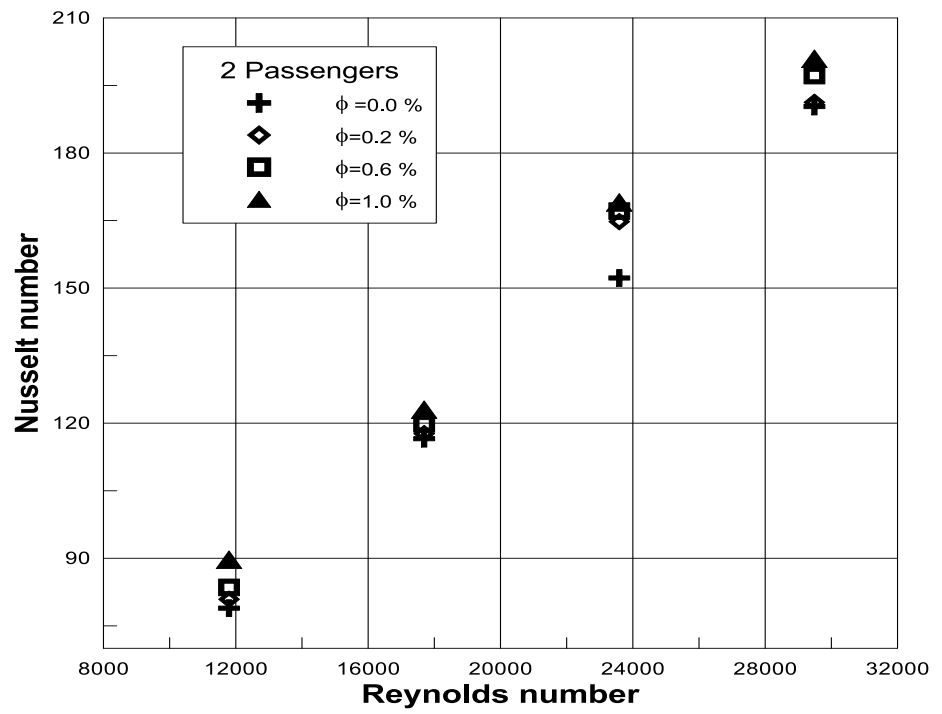

Fig.5: Variation of $\mathrm{Nu}$ number with Re number for 2 passengers at variable Nanofluid concentrations

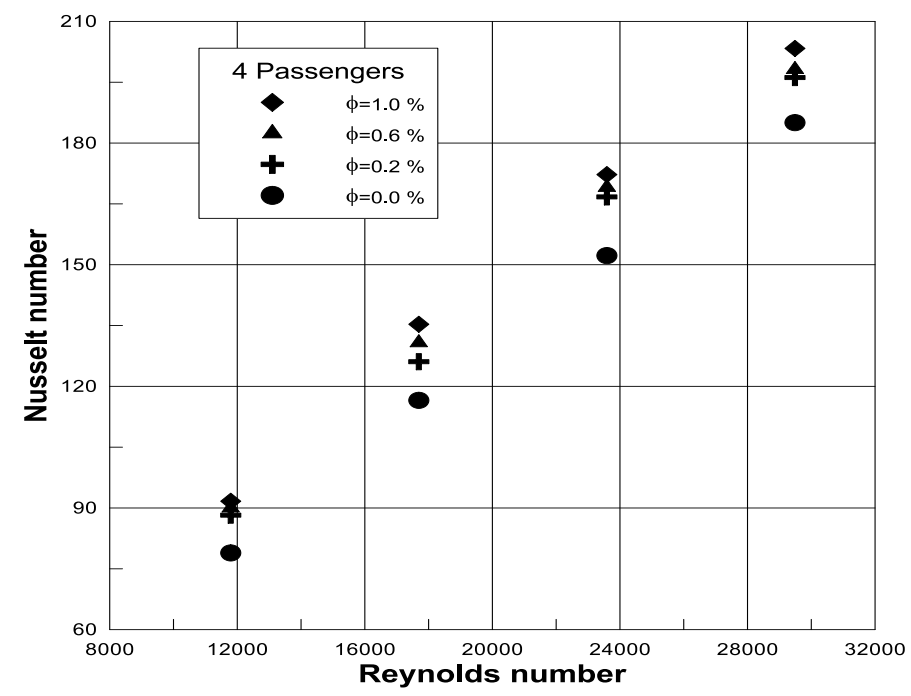

Fig.6: Variation of $\mathrm{Nu}$ number with Re number for 4 passengers at variable Nanofluid concentrations 
Variation of $\mathrm{Nu}$ number with variable Nanofluid concentrations for 2 and 4 passengers at variable water flow rate is shown in Figures (7, and 8). Both illustrate that with increasing Nanofluid concentration Nusselt number increased according to the water flow rate inside car radiator.

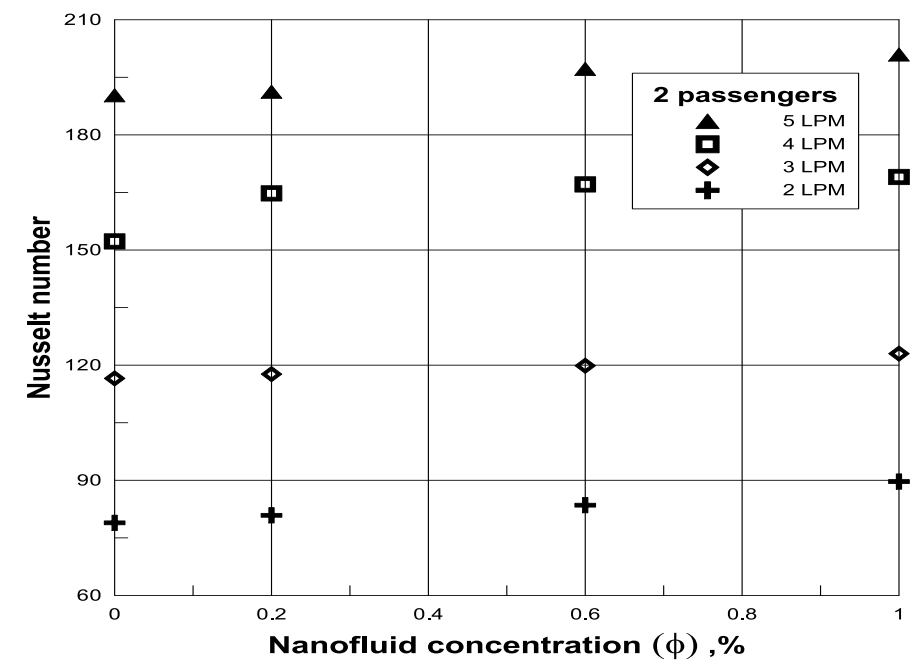

Fig.7: Variation of $\mathrm{Nu}$ number with variable Nanofluid concentrations for 2 passengers at variable water flow rate

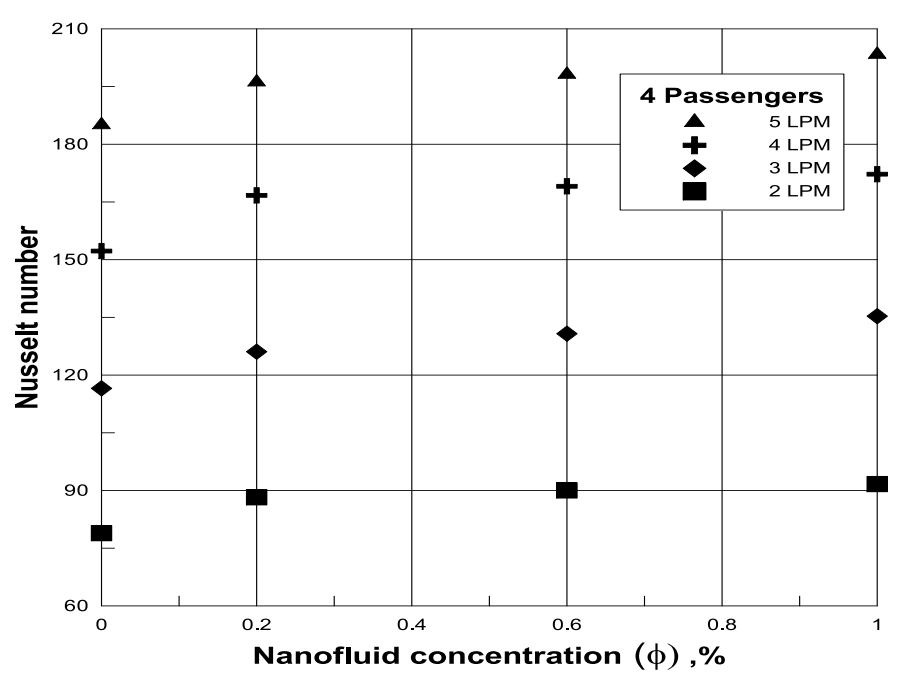

Fig.8: Variation of $\mathrm{Nu}$ number with variable Nanofluid concentrations for 4 passengers at variable water flow rate

The enhancement in the system for Nusselt number was calculated using equation (18) where a comparison between using Nanofluid in the system and without using it. As shown in Figure (9) illustrates the enhancement percentage in Nusselt number with variation of Nanofluid concentration for different flow rates, where enhancement percentage increases with increasing volume concentration and flow rate. 


$$
E=\frac{N u(\varphi)-N u(\text { basefluid })}{N u(\text { basefluid })} \times 100
$$

Where $\mathrm{E}$ is the enhancement in the heat transfer.

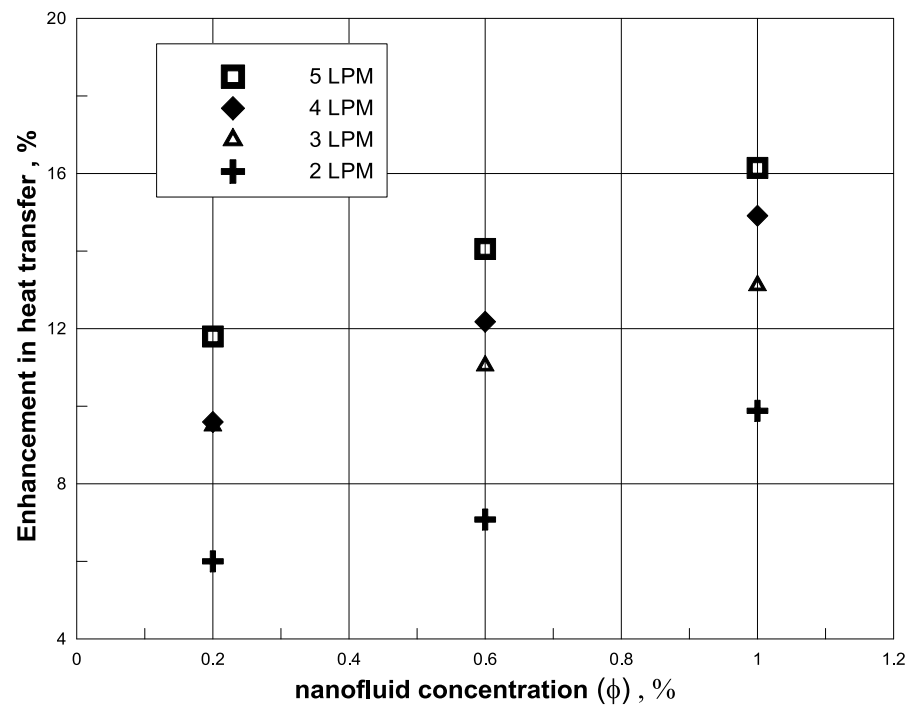

Fig.9: Effect of Nanofluid concentrations and water flow rate on enhancement in heat transfer

The second part for results was to monitor the gases emissions by using Nanofluids inside CR. As shown in Figures (10, and 11) carbon monoxide emissions increase with increasing vehicle speed but decrease with number of passengers and Nanofluid concentration.

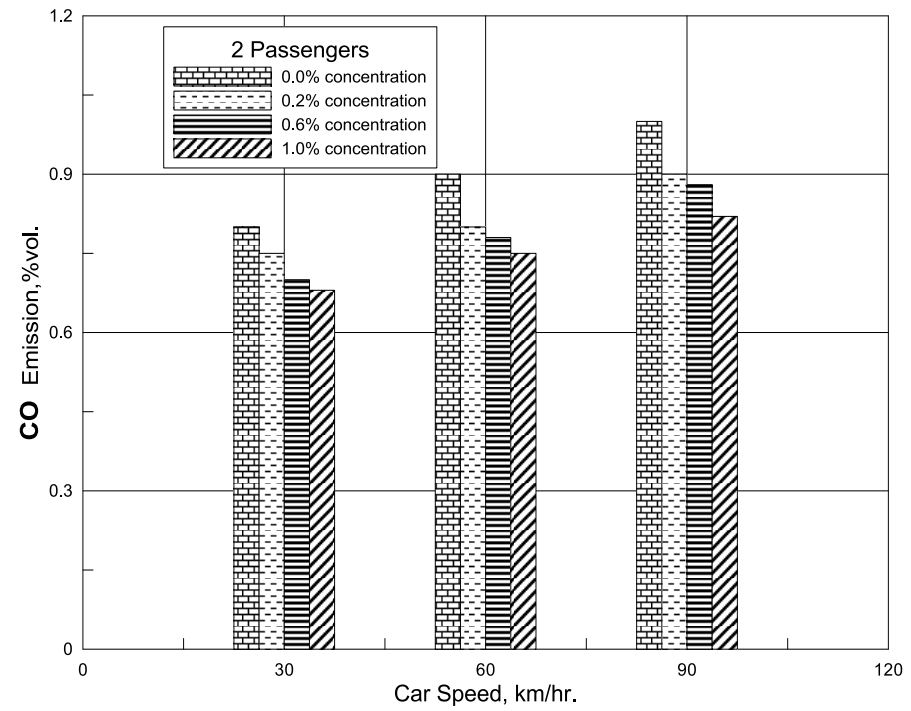

Fig.10: Variation of CO emission with vehicle speed at different Nanofluid concentration for 2 passengers 


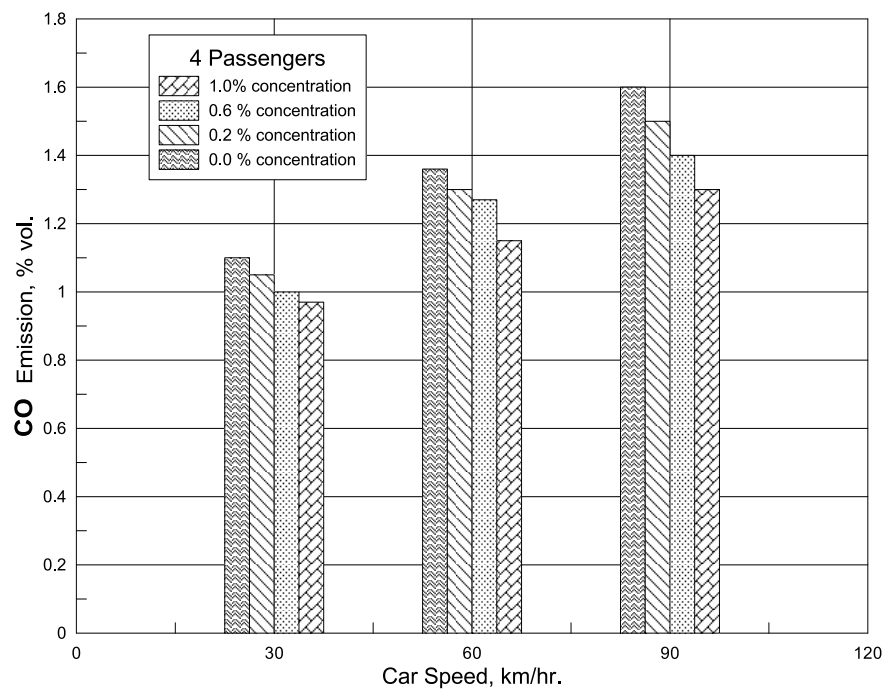

Fig.11: Variation of $\mathrm{CO}$ emission with vehicle speed at different Nanofluid concentration for 4 passengers

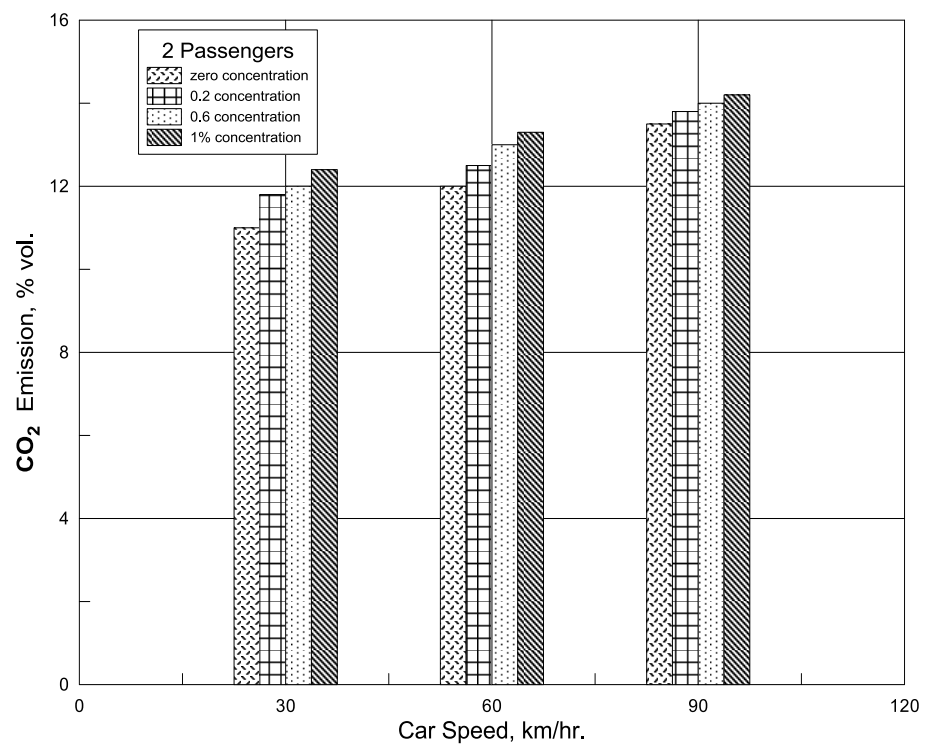

Fig.12: Variation of $\mathrm{CO}_{2}$ emission with vehicle speed at different nanofluid concentration for 2 passengers

Variation of $\mathrm{CO}_{2}$ emissions was plotted with vehicle speed as shown in Figures $(12,13)$ for 2 and 4 passengers, where the carbon dioxide decrease with increasing nanofluid concentration and number of passengers for decreasing vehicle speed. 


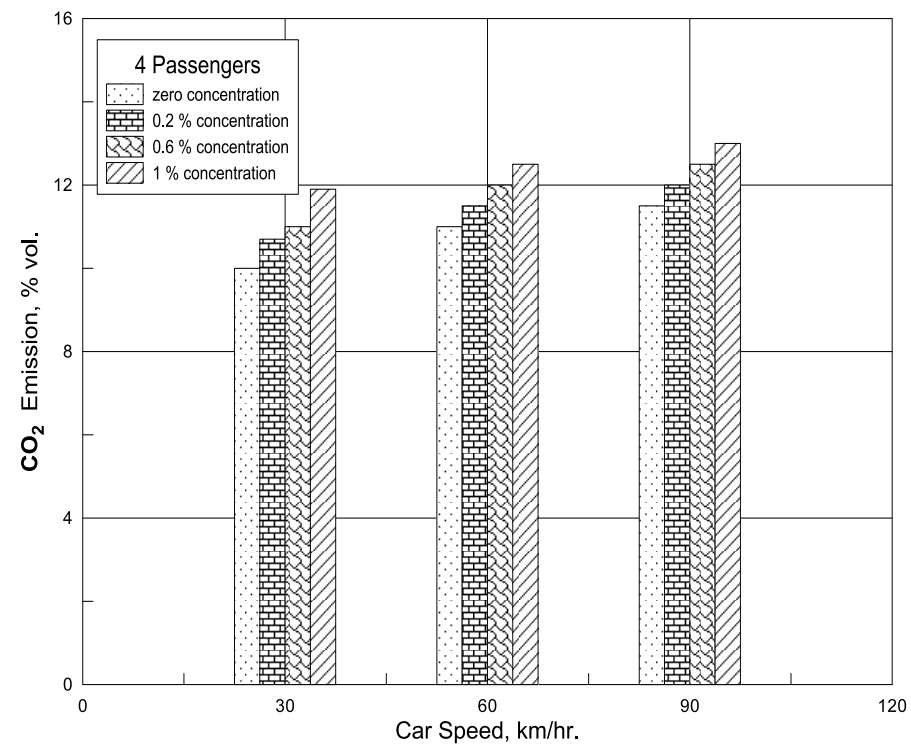

Fig.13: Variation of $\mathrm{CO}_{2}$ emission with vehicle speed at different Nanofluid concentration for 4 passengers

Nitrogen oxide is an irritant gas, which at high concentrations causes inflammation of the airways. So, it is important to minimize its emissions to atmosphere. As vehicle speed increase NOx emission increases as shown in figures (14, and 15) for both 2 and 4 passengers but with using nanofluids as cooling fluid inside CR its noticed that amount of nitrogen oxide decreases with increasing nanofluids.

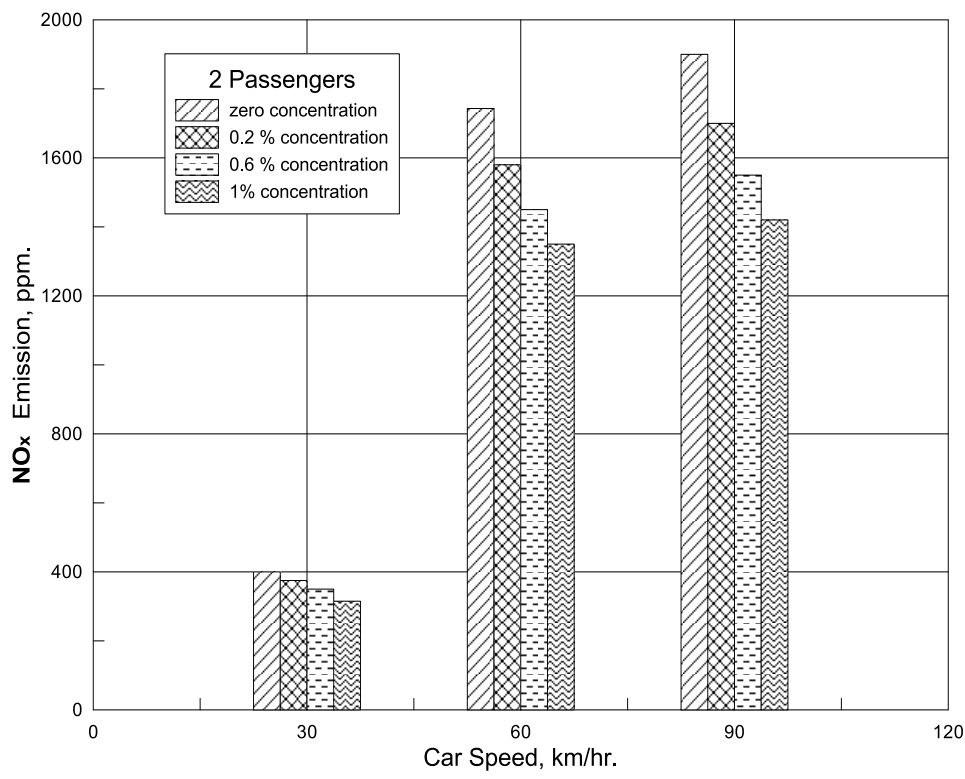

Fig.14: Variation of $\mathrm{NO}_{\mathrm{X}}$ emission with vehicle speed at different nanofluid concentration for 2 passengers 


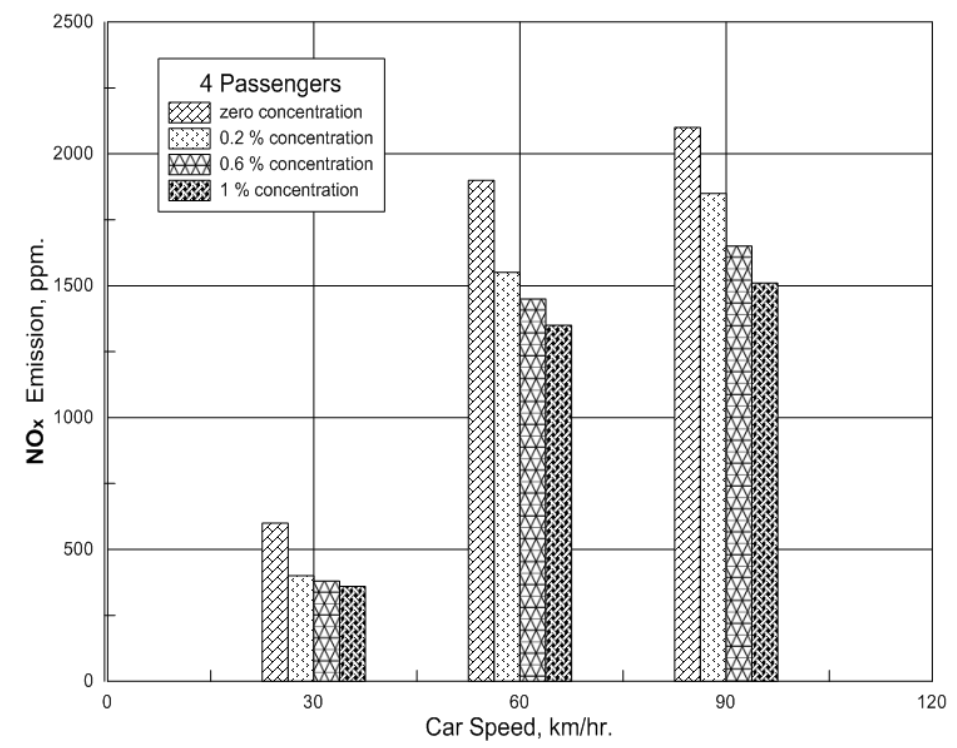

Fig.15: Variation of $\mathrm{NO}_{\mathrm{X}}$ emission with vehicle speed at different Nanofluid concentration for 4 passengers

\section{Conclusion}

Analysis of the obtained results illustrates that:

- Using $\mathrm{AL}_{2} \mathrm{O}_{3}$ Nanofluid inside car radiator enhance the heat transfer characteristics as represented in Nusselt number for both 2 and 4 passengers are applied with variable flow rate and Reynolds number.

- As volume nanofluid concentration increase the Nusselt number increases so as this result the bulk volume of car radiator can be decreased. Also, on other side the gas emissions were reduced with increasing nanofluid concentration

- High car speeds generate higher rates of $\mathrm{NO}_{\mathrm{X}}$ emissions which reached more than 4 times at $90 \mathrm{~km} / \mathrm{hr}$. related to that concentration at $30 \mathrm{~km} / \mathrm{hr}$.

- High Nano-material concentrations generated lower $\mathrm{NO}_{\mathrm{X}}$ emissions for all test speeds

- Low car speed generated relative low $\mathrm{NO}_{\mathrm{X}}$ emission for the Nano-material additives.

\section{Nomenclature}

$\begin{array}{lll}\mathrm{A} & \text { Area, } & \mathrm{m}^{2} \\ C_{P} & \text { Specific heat, } & \mathrm{J} / \mathrm{kg} \cdot \mathrm{K} \\ \mathrm{Q} & \text { Heat transfer rate, } & \mathrm{W} \\ \mathrm{m} & \text { Mass flow rate } & \mathrm{kg} / \mathrm{Sec} \\ \mathrm{T} & \text { Temperature, } & { }^{\circ} \mathrm{C} \\ \mathrm{K} & \text { Thermal conductivity, } & \mathrm{W} / \mathrm{m} . \mathrm{K} \\ \mathrm{h} & \text { Heat transfer coefficient, } & \mathrm{W} / \mathrm{m}^{2} . \mathrm{K} \\ \mathrm{L} & \text { Length of flattened tube of CR, } & \mathrm{m}\end{array}$




$\begin{array}{lll}\mathrm{W} & \text { Width of flattened tube of CR, } & \mathrm{m} \\ \mathrm{H} & \text { Height of flattened tube of CR, } & \mathrm{m} \\ \mathrm{d} & \text { Hydraulic Diameter } & \mathrm{m} \\ \text { Greek } & \text { Symbols } & \\ \mathrm{Re} & \text { Reynolds number, } & \\ \varphi & \text { Volume concentration, } & \% \\ \mu & \text { Viscosity, } & \mathrm{kg} / \mathrm{m} . \mathrm{s} \\ \rho & \text { Density, } & \mathrm{kg} / \mathrm{m}^{3} \\ \mathrm{Nu} & \text { Nusselt number, } \\ \mathrm{Subscripts} & \\ \mathrm{f} & \text { Fluid } & \\ \mathrm{p} & \text { Particle } & \\ \mathrm{nf} & \text { Nanofluid } & \\ \mathrm{hy} & \text { Hydraulic } \\ \mathrm{Abbreviation} & \\ \mathrm{NF} & \text { Nanofluid } \\ \mathrm{CR} & \text { Car Radiator } & \\ \mathrm{CO} & \text { Carbon Monoxide } \\ \mathrm{CO} & \text { Carbon Dioxide } \\ \mathrm{NO}_{\mathrm{X}} \quad \text { Nitrogen Oxide } \\ \text { References }\end{array}$

[1] H. M. Ali, H. Ali, H. Liaquat, H. T. B. Maqsood and M. A. Nadir, "Experimental investigation of convective heat transfer augmentation for car radiator using ZnOewater nanofluids," Energy, vol. 84, pp. 317-324, 2015.

[2] M. Ebrahimi, M. Farhadi, K. Sedighi and S. Akbarzade, "Experimental Investigation of Force Convection Heat Transfer in a Car Radiator Filled with SiO2-water Nanofluid," International Journal of Engineering, vol. 27, pp. 333340, 2014.

[3] D. Sandhya, M. C. S. Reddy and V. V. Rao, "Improving the cooling performance of automobile radiator with ethylene glycol water based $\mathrm{TiO} 2$ nanofluids," International Communications in Heat and Mass Transfer, vol. 78, p. 121-126, 2016.

[4] A. R. Esmaeili Sany, M. H. Saidi and J. Neyestani, "Experimental Prediction of Nusselt Number and Coolant Heat Transfer Coefficient in Compact Heat Exchanger Performed with $\varepsilon$-NTU Method," The Journal of Engine Research, vol. 18, 2010.

[5] B. P. S. Tomar and A. Tripathi, "Experimental Study of Heat Transfer of a Car Radiator with Nano fluid- A12O3/Water mixture as Coolant," International 
Journal of Advanced Research in Science, Engineering and Technology, vol. 2, no. 9, pp. 830-837, 2015.

[6] K. Leong, R. Saidur, S. Kazi and A. Mamun, "Performance Investigation of an Automotive Car Radiator Operated with Nanofluid-Based Coolants (Nanofluid as a Coolant in a Radiator)," Applied Thermal Engineering, vol. 30, pp. 26852692, 2010.

[7] M. Raga, R. Vijayan, S. Suresh and R. Vivekananthan, "Effect of Heat Transfer Enhancement and NOx Emission using AL2O3/Water Nanofluid as Coolant in CI Engine," Indian journal of engineering \& material science, vol. 20, pp. 443-449, 2013.

[8] A. M. Hussein, R. Bakar, K. Kadirgama and K. Sharma, "Heat Transfer Enhancement using Nanofluids in an Automotive Cooling System," International Communications in Heat and Mass Transfer, vol. 53, p. 195-202, 2014.

[9] S. Senthilraja, K. Vijayakumar and R. Gangadevi, "Effect of Specific Fuel Consumption and Exhaust Emissions of Four Stroke Diesel Engine with CUO/Water Nanofluid as Coolant," Archive of mechanical engineering, vol. LXIV, pp. 111-121, 2017.

[10] M. M. Ahmed, "Performance of Automotive Engines Working With Controllable Thermal Management System and Nanofluids as Cooling Medium", Ph D. Dissertation, Faculty of Eng., Helwan University, Egypt 2018.

[11] M. Naraki, S. Peyghambarzadeh, S. Hashemabadi and Y. Vermahmoudi, "Parametric Study of Overall Heat Transfer Coefficient of CuO/Water Nanofluids in a Car Radiator," International Journal of Thermal Sciences, vol. 66, pp. 82-90, 2013.

[12] S. J. Kline and F. A. McClintock, "Describing Uncertainties in Single-Sample Experiments," in Mechanical Engineering, 1953, pp. 3-8.

[13] V. Gnielinski, "New Equations for Heat and Mass Transfer in the Turbulent Flow in Pipes and Channels," NASA STI/Recon Technical Report A, vol. 75, no. 22028, 1975.

[14] B. Petukhov, "Heat Trasfer and Friction in Turbulent Pipe Flow with Veriable Physicsl Properties," Advances in heat transfer, vol. 6, pp. 503-564, 1970.

[15] F. Dittus and L. Boelter , "Heat Transfer in Automobile Radiators of Tubular type.," Berkeley, CA: University of California , vol. 2, pp. 13-18, 1930. 